UDC $13+930.1$

LBC $87.3(2)+63$

\title{
PHILOSOPHY OF HISTORY OF N.A. BERDYAEV: THE EXISTENTIAL END OF HISTORY OR AN APOCALIPSIS INTERIORIZED
}

\author{
Artem M. Hamidulin \\ Nizhny Novgorod Theological Seminary, Nizhny Novgorod, Russian Federation; \\ Kozma Minin Nizhny Novgorod State Pedagogical University (University of Minin), \\ Nizhny Novgorod, Russian Federation
}

\begin{abstract}
The article analyzes the philosophy of history of N. A. Berdyaev. The starting point of the article is the thesis about the relationship between the problematics of time and historical science. It is noted that for Berdyaev, the philosophy of time is one of the main themes of his philosophy of history. Attention is drawn to the feeling of dissatisfaction experienced by Berdyaev with the fluidity and mobility of time. The perception of the philosopher of time as solicitude and, to a large extent, as an evil or a disease that must be overcome is explicated. The reality of the past and future times equal to the present is revealed. The author demonstrates the bliss inspired by actual experience and philosophy of time. Concept of psychological time of Augustine, which justifies the reality of the past, present and future. Teaching about the instantaneity of the present as a point of interaction between time (historical and cosmic) and eternity (celestial time) of Berdyaev is considered. The possibility of experiencing this kind of moment is considered by Berdyaev on the basis of the existential dimension of time that flows in the depths of the human spirit. The author notes the influence of the teaching about the moment by Danish philosopher Swren Kierkegaard on Berdyaev. A parallel is drawn between teaching on the meaning of the moment by Berdyaev and the concept of "kairos" of German theologian Paul Tillich. The article analyzes eschatology of Berdyaev, which determines his belonging to the traditions of the Russian religious philosophy of history. Two possible ways to overcome time are revealed: in an instant, i.e. repeatedly during human life, and as a result of the total end of history, which, according to Berdyaev, is also to a large extent a phenomenon of the existential sphere of being. According to Berdyaev, this kind of exit from time gives the opportunity to learn the meaning of history, on the one hand, and to free oneself from the enslaving power of time, on the other. It is concluded that Berdyaev understood the end of history existentially as a special spiritual experience that allows us to overcome time and look at history in terms of eternity.
\end{abstract}

Key words: philosophy of history, Berdyaev, man, existence, the end of history, Eschaton, Apocalypse, spiritual experience.

УДК $13+930.1$

ББК $87.3(2)+63$

\section{ФИЛОСОФИЯ ИСТОРИИ Н.А. БЕРДЯЕВА: ЭКЗИСТЕНЦИАЛЬНЫЙ КОНЕЦ ИСТОРИИ, ИЛИ АПОКАЛИПСИС ИНТЕРИОРИЗОВАННЫЙ}

\section{Артём Маратович Хамидулин}

Нижегородская духовная семинария, г. Нижний Новгород, Российская Федерация; Нижегородский государственный педагогический университет им. Козьмы Минина (Мининский университет), г. Нижний Новгород, Российская Федерация

Аннотация. В статье анализируется философия истории Н.А. Бердяева. Исходным положением исследования является тезис о взаимосвязи проблематики времени и исторической науки. Отмечается то, что для Бердяева 
философия времени служит одной из основных тем его философии истории. Обращается внимание на переживаемое мыслителем чувство неудовлетворенности текучестью и подвижностью времени. Эксплицируется восприятие философом времени как заботы и в значительной степени как зла или болезни, которые следует преодолеть. Выявляется равная настоящему реальность прошлого и будущего времен. Демонстрируется инспирированная собственным опытом и философией времени блаженного Августина концепция психологического времени, чем и обосновывается реальность прошлого, настоящего и будущего. Рассматривается учение Бердяева о мгновенности настоящего как точки взаимодействия времени (исторического и космического) и вечности (небесного времени). Возможность переживания подобного рода мгновения мыслится им на основании экзистенциального измерения времени, которое протекает в глубине человеческого духа. Отмечается влияние на философа учения о мгновении датского мыслителя Сёрена Кьеркегора. Проводится параллель между учением Бердяева о значении мгновения и представлением немецкого теолога Пауля Тиллиха о «кайросе». Анализируется эсхатология Бердяева, определяющая его приверженность традициям русской религиозной философии истории. Обнаруживаются два возможных преодоления времени: в мгновении, то есть многократно в течение человеческой жизни, и в результате тотального конца истории, который, согласно Бердяеву, также в значительной степени есть явление экзистенциальной сферы бытия. Такого рода выход из времени дарует, по его мнению, возможность познания смысла истории, с одной стороны, и освобождения от порабощающей власти времени - с другой. В заключение делается вывод об экзистенциальном понимании мыслителем конца истории как особого духовного опыта, который позволяет преодолеть время и взглянуть на историю с точки зрения вечности.

Ключевые слова: философия истории, Бердяев, человек, экзистенция, конец истории, эсхатон, апокалипсис, духовный опыт.

Проблема времени является неотъемлемой частью философии истории. Известный французский историк-медиевист Жак Ле Гофф формулирует эту мысль в своем сочинении «История» весьма недвусмысленно: «История - это наука о времени» [Ле Гофф $2013,171]$. Более образно идею о том, что ни один изучающий историю специалист не может обойти проблематику времени, выражал другой французский историк и представитель историографической французской школы «Анналов» Фернан Бродель: «Историк ни на минуту не может выйти за пределы исторического времени. Время липнет к его мысли, как земля к лопате садовника» [Бродель 1977, 134]. Здесь уже сам выбор метафоры, сравнивающей труд историка с трудом садовника, копающего землю, отсылает нас к образу работы «копания» историка в прошлом и имплицитно содержит в себе указание как минимум на прошлое и настоящее, от которых хотя и можно в процессе работы абстрагироваться, но совершенно невозможно уйти полностью. Для творчества Бердяева связь проблематики истории, человека и времени закономерна. При этом примечательно, что особенности мироощущения философа наложили отпечаток на его историософскую систему, в которой ключевым элементом оказывается человек, живущий между временем и вневременностью. Очевидно, что интеллектуальный труд мыслителя, рефлексирующего над проблемой истории и предполагающего, как в случае Бердяева, построение собственной метафизики истории, невозможен без рассмотрения и философского анализа проблематики взаимоотношений категории времени и категории вечности.

«Философия истории есть в значительной степени философия времени», - утверждает Бердяев в трактате «О рабстве и свободе человека. Опыт персоналистической философии» (1939) [Бердяев 1995, 155]. В ранней историософской работе «Смысл истории» (1923) проблема времени именуется мыслителем «самой трагической проблемой метафизики истории» [Бердяев 2002, 183]. Следующий отрывок позволяет нам лучше понять представление Бердяева о времени и вечности в зрелый период его творческой биографии: «Мысль о времени мне представляется глубоко противоречивой. Будущее легко может стать прошлым, прошлое - будущим. Время всегда было для меня настоящей болезнью. Я слишком спешил преодолеть время и этим подчинял ему себя. Я безумно спешил к концу, не к концу-смерти, а к концу-вечности, к трансцендированию времени» [Бердяев 1999, 307]. Таким образом, из данного фрагмента биографии философа можно эксплицировать то, что, во-первых, мысль о времени представляла действительно острую заботу, а также 
чувство беспокойства и неудовлетворенности для Бердяева, и в этом отношении болезнь времени приобретает совершенно иные смысловые аспекты, и, во-вторых, то, что мыслитель обнаруживает течение и подвижность времени, способность времени подчинять себе человека, как и способность человека в каком-то особом смысле трансцендировать, превозмочь время.

Русский философ, постулируя в своей системе факт наличия небесного времени и вечности (а также времени космического и времени исторического) как особого рода темпоральной целостности высказывает следующую мысль: «...историческая действительность, отошедшая в прошлое, не есть умершая историческая действительность; не менее реальна она, чем та, которая свершается в данное мгновение, или та, которая будет свершаться в будущем и которую мы тоже не воспринимаем» [Бердяев 2002, 74]. Данное высказывание фактически утверждает интересную мысль: получается, что, по мнению Бердяева, не только настоящее реально, но и прошлое и будущее, причем их реальность вполне сопоставима. Конечно, в другом месте (в ходе критического рассмотрения идеи прогресса) Бердяев замечает, что прошлое все же более реально, чем будущее [Бердяев 2002, 191], но тем не менее предыдущая мысль кажется отнюдь не случайной в системе мысли философа, поскольку если история есть взаимоотношение времени и вечности, а настоящее, уходя в прошлое, становится частью времени небесного, то будущее также приходя в настоящее, приходит в некотором смысле из вечности, а значит, также в особом смысле, уже существует. Эта онтологическая по своей сути мысль Бердяева о том, что прошлое и будущее существуют в настоящее время в силу того, что они причастны вечности, обладает возможностью антропологического или психологического транспонирования. Это означает, что являющаяся частью сферы духа история предполагает не только переданное и бытующее в настоящее время повествование о прошлом, но и «воспоминание» о будущем как знание-предположение об истории, обращенной в будущее, представляет из себя момент человеческого сознания, факт его психологической активности.
В этом контексте нельзя не провести параллель между представлением Бердяева о природе времени и учением о времени блаженного Августина, которое, между прочим, русский философ именует «гениальным» [Бердяев 2002, 71-72]. Обнаруживающийся у Бердяева выход из сферы онтологии времени в сферу антропологии времени представляется родственным психологической или субъективной теории времени, разработанной блаженным Августином. Христианский богослов именно в антропологии (конкретно в душе человека) усматривает основание для разделения времени на прошлое, будущее и настоящее, которые, соответственно, соотносятся с такими душевными актами, как память (memoria), ожидание (expectation) и внимание (attention). Это означает то, что для блаженного Августина разделенное время во многом есть не что иное как результат человеческого восприятия, модус его сознания [Августин Аврелий 1991, 297]. Так, Августин приходит к следующему умозаключению, которое Бердяев и цитирует на страницах своего трактата «Я и мир объектов» (1934): «Совершенно ясно теперь одно: ни будущего, ни прошлого нет, и неправильно говорить о существовании трех времен: прошедшего, настоящего и будущего. Правильнее было бы, пожалуй, говорить так: есть три времени - настоящее прошедшего, настоящее настоящего и настоящее будущего» [Бердяев 1994, 284; Августин Аврелий 1991, 297]. Это вполне соотносится как с учением Бердяева о внутреннем, экзистенциальном времени, которое причастно вечности как вечному настоящему [Бердяев 2002, 73], так и со следующей его мыслью из того же трактата: «...прошлое и будущее, как существующее, входит в состав настоящего» [Бердяев 1994, 285]. То же самое будет справедливо, по Бердяеву, и для эсхатологического будущего, которое хотя еще не наступило, но в определенном смысле уже есть. В этом и обнаруживается влияние мысли блаженного Августина на мысль Бердяева. Различие же философии времени последнего от учения блаженного Августина заключается в том, что русский мыслитель все же распространяет категорию времени на небесную сферу, даже в вечность привнося известный исторический динамизм, который обосновывается у Бердя- 
ева глубинной «добожественной» свободой. Следует заметить, что, согласно мысли русского философа, всякое прошлое или будущее есть время разорванное, и вполнелогично, что на рубеже эпох эта разорванность ощущается наиболее остро. Примечательно в связи с этим, что Сэмюэл Мойн (Samuel Moyn), профессор истории Йельского университета, анализируя западную христианскую философию истории, связывает уменьшение буквально понимаемых апокалиптических ожиданий в христианской проповеди в V в. с падением Рима под ударами вестготов в 410 г. - христианским писателям необходимо было интерпретировать учение о скором конце истории в связи с падением Рима, событием, безусловно, апокалиптического масштаба, после которого, однако, ожидаемый скорый конец света все же не наступил [Moyn 2009, 430]. Вероятно, Бердяева, который на себе испытал все ужасы происходящих событий первой половины XX в., волновала схожая проблематика, стратегией же решения для него стал путь внутреннего осмысления идеи конца истории. Другими словами, Бердяев, вслед за обоснованием того, что разделение времени на прошлое, настоящее и будущее является во многом фактом человеческого сознания, стремится рассмотреть возможность преодоления «больного» времени также в экзистенциальных категориях.

В такой ситуации спасение видится мыслителю в полноте настоящего, однако не такого настоящего, которое есть метущаяся, неуловимая часть времени, но настоящего, понимаемого как часть вечности, то есть как «...выход из времени, не атом времени, а атом вечности, как говорит Киркегардт...» [Бердяев 1995, 157; Кьеркегор 2014, 111]. Упоминание имени датского религиозного философаэкзистенциалиста Сёрена Кьеркегора в труде Бердяева «О рабстве и свободе человека. Опыт персоналистической философии» (1939) не случайно. Ко времени написания Бердяевым цитируемых выше строк уже вышла значительная книга Л.И. Шестова о датском мыслителе «Киркегард и экзистенциальная философия (Глас вопиющего в пустыне)» (1936). Помогал в издательстве этой книги среди прочих и Бердяев, назвавший впоследствии в отдельной статье «Лев Шестов и Кир- кегаард» эту книгу Шестова «...быть может лучшей из его книг...» [Бердяев 1936, 375]. Для Бердяева, как и для датского философа, понятие «мгновение» связано не только со сферой личного экзистенциального времени, но и со сферой времени исторического. Так, например, в трактате «Понятие страха» (1844) Кьеркегор высказывает мысль о том, что время имеет смысл только для личностного бытия, поскольку для лишенной сознания природы время лишено значения. В переживаемом же человеком мгновении времени Кьеркегор усматривает некоторую соразмерность вечности, причем само возникающее во мгновении соотнесение времени и вечности обосновывает возможность понимания временности и историчности как таковых: «Мгновение - это та двузначность, в которой время и вечность касаются друг друга, и вместе с тем полагается понятие временности, в которой время снова и снова разделяет вечность, а вечность снова и снова пронизывает собою время» [Кьеркегор 2014, 111-112]. Мы знаем какое личностно ангажированное отношение у Бердяева было по отношению к вечности. «Мне хотелось, чтобы времени больше не было... а была лишь вечность», - пишет Бердяев в одном из своих сочинений [Бердяев 1999, 39], поэтому полнота переживаемого мгновения настоящего и являлась для русского философа диалектическим преодолением временности.

Заметим, что несколькими годами ранее публикации книги Шестова о Кьеркегоре вышла статья Шестова «Николай Бердяев (Гнозис и экзистенциальная философия)», в которой Шестов анализирует творческие пересечения философии Бердяева и Кьеркегора через призму философии экзистенциализма и отмечает всю сложность и непохожесть философского экзистенциализма двух мыслителей. Однако в позднейший период своего творчества Бердяев сам называет себя экзистенциалистом: «Я имею основание считать себя экзистенциалистом, хотя в большей степени мог бы назвать свою философию философией духа и еще более философией эсхатологической» [Бердяев 1995, 294]. Очевидно, что отсылка к Кьеркегору значима для аналитики творчества Бердяева, но даже не тем, что, совершая шаг из «больного», рационализиро- 
ванного времени в сторону вечности, Бердяев выступает в духе экзистенциализма, но скорее тем, что мысль Кьеркегора оказывается глубоко созвучна пониманию исторической темпоральности, которое мы обнаруживаем у русского философа, его стремлению преодолеть разорванное время, трансцендируя его в сакральную вечность. Понимание настоящего через внутреннюю сферу человеческого существования в качестве реальности, во мгновении инкорпорированной в вечность, открывает образ целостного, исцеленного времени, которое, по Бердяеву, было бы лишенным прошлого и будущего, но явилось бы «...вечным настоящим или вечным сегодняшним днем...» [Бердяев 2002, 73]. С этой точки зрения становится понятна и критика Бердяевым разного рода утопических общественно-политических концепций: то обещающих человечеству счастье в неопределенном будущем, то выдающих за образец гармоничной жизни сценарии из глубокого прошлого. Настоящая же творческая работа, призванная улучшить социально-политическую ситуацию, по мнению мыслителя, должна быть ориентирована лишь на такое вечное настоящее, которое примиряет в себе прошлое с будущим.

В то же время как возможен прорыв временного в вечность, так и наоборот, согласно мнению русского историософа, возможен прорыв вечного во временное, которое также представляет собой благостное мгновение. Примечательно то, что Бердяев сопоставляет свое понимание этого прорыва вечности во временное через экзистенциальное время с понятием «кайрос» как полноты времени, встречающемся у его современника - немецкого теолога П.Й. Тиллиха [Бердяев 1995, 157]. Для немецкого теолога момент сопричастности человека вечности необходим для познания временности, а значит, и историчности бытия: «...не существует другой возможности оценить время, кроме как увидеть его в свете вечного. Чтобы оценить нечто, мы должны частично находиться внутри него, частично - вне...» [Тиллих 2005, 170]. Бердяев так же, как и Тиллих, приводит в качестве примера мгновенного проявления из сферы экзистенциального времени воплощение Сына Божия, согласно христианскому его понима- нию [Тиллих 1995, 216-235]. Именно из области экзистенциального времени возникает в историческом процессе настоящая новизна. Так, результат творческой деятельности субъекта истории экстериоризируется во времени историческом. Таким образом, согласно точке зрения Бердяева, выход из «больного» времени и вход в вечность возможен во мгновении настоящего.

Н.И. Безлепкин обращает внимание на понимание Бердяевым историософии как своего рода пророчества [Безлепкин 2017, 119132]. Действительно, у Бердяева встречается следующее размышление: «...в философии истории раскрывается не объективная данность, не воспринятие фактичности исторического процесса, а пророческое проникновение в прошлое, которое есть также и проникновение в будущее» [Бердяев 2002, 44]. Наподобие того, как пророческие тексты нуждаются в расшифровке, уже сам характер этого высказывания указывает на необходимость его толкования. Помимо того что философия истории предполагает скорее умозрение по поводу истории, чем ее фактологический анализ, и идеи того, что, зная прошлое, можно предвидеть будущее, русский философ высказывает в этом утверждении мысль о том, что какое бы то ни было рассуждение о смысле и метафизике истории возможно лишь в свете конца исторического процесса. Утверждая необходимость момента эсхатологичности или апокалиптичности для философии истории Бердяев замечает, что вся русская религиозная философия на своих вершинах (к которым мыслитель относит П.Я. Чаадаева, славянофилов, Вл.С. Соловьева, К.Н. Леонтьева, Ф.М. Достоевского [Бердяев 2002, 181]) была увлечена, с одной стороны, философией истории, а с другой - как раз темой конца времен. Надо сказать, в этом отношении Бердяев продолжает традицию русской мысли. Однако философа свободы не устраивают предлагаемые современными ему эсхатологическими учениями сценарии - как предполагающие бесконечное эволюционное развитие, именуемое им оккультически-теософическим кошмаром, так и религиозные эсхатологические сценарии, предполагающие вечность адских мучений, или мистические сценарии, призывающие к растворению человеческой 
личности в божестве. За всеми тремя апокалиптическими моделями Бердяев видит обесценивание исторического процесса и, как результат, идеологический подрыв самой возможности постановки вопроса о смысле истории. В связи с этим философ предлагает собственное видение эсхатологического сценария.

Закономерно, что проблематика конца истории видится Бердяеву связанной со временем. Для осмысления истории и времени в данном контексте необходимо взглянуть на них со стороны, то есть из перспективы вечности. Это представляется мыслителю возможным двояким образом. С одной стороны, в мгновении настоящего каждый человек уже способен приобщиться вечности через глубины собственного духа. Однако человек также склонен и выпадать из обретенной им во мгновении вечности, вновь «проваливаясь» во временность. Так что, с другой стороны, перед человечеством открывается второй, итоговый выход в вечность, или возвращение временности в вечность, которое возможно через совершенный конец этого мира и, соответственно, «плохого» времени. Это тем не менее должно пониматься не как завершение истории вообще, но как переход от разорванного времени в небесное время и в качестве перехода от земной истории в историю небесную.

Для историософской мысли Бердяева оба этих сценария, второй из которых непосредственно связан с будущим и эсхатологией, обладают также двойным смыслом. Первый из них именуется философом гносеологическим и подразумевает, что выход из времени в вечность освобождает человека от власти объективированного пространства истории и позволяет ему эту историю осмыслить и понять (тем самым превозмочь, победить время). Второй аспект именуется Бердяевым социологическим и указывает, что выход из временности в вечное освобождает человека не только от некоей теоретически постигаемой исторической власти, но и от вполне конкретной, лишающей человека свободы власти общественных институций. Оба аспекта в итоге позволяют во мгновении настоящего освободиться от тоталитарной власти разорванного времени и познать историю в ее единстве, что, очевидно, строго необходимо мыслителю для философского постижения исто- рии, ибо ее смысл, как он считает, «...лежит за пределами самого исторического времени, в перспективе эсхатологической» [Бердяев 1995, 159].

Сам же эсхатон - предел истории и времени - предстает для Бердяева в виде такого рода двойственности, которая предполагает как общественно-исторический апокалипсис, так и апокалипсис персональный. Для верного понимания этой мысли необходимо вспомнить о потенции, содержащейся в философско-исторической концепции Бердяева, которая предполагает возможность внутреннего переживания исторических событий прошлого так же, как и возможность в мгновении настоящего прорываться духом в вечность, что, следовательно, предполагает возможность постижения не только исторического прошлого, но и исторического будущего. В этом личностном постижении прошлого и будущего можно заметить значительный профетический дух историософской системы Бердяева. Тем не менее необходимо сказать, что мыслитель, не исключая события конца истории из самой истории, все же преимущественно излагает личностное и экзистенциальное его понимание. Причиной этому является то, что конец истории означает одновременно и конец времени, следовательно, конец истории невозможно объективировать, а значит, и осмыслить в рамках временности общественно-исторических отношений. Следовательно, рассуждать об эсхатоне можно лишь отчасти при помощи темпоральных категорий, поэтому здесь на помощь приходит внутреннее, психологическое измерение времени, так как именно оно у Бердяева оказывается причастным вечности. Выражаясь терминологией самого философа, предлагаемый им выход предполагает осмысление конца истории как события времени персонального: «Конец истории есть событие времени экзистенциального. И вместе с тем, это событие нельзя мыслить вне истории. Конец истории, совершающийся в экзистенциальном времени, совершается и “по ту сторону" и “по сю сторону”» [Бердяев 1995,159$]$. Таким образом, Бердяев, не отрицая исторического факта конца истории, отводит ему преимущественное место в экзистенциально-духовном измерении. 
В заключение можно сформулировать выводы относительно следующих рассмотренных в статье аспектов философии истории Н.А. Бердяева: 1) стремление философа преодолеть время, его желание вечности; 2) представление Бердяева о психологических причинах существования прошлого, настоящего и будущего в духе блаженного Августина; 3) взгляды на потенциал мгновения настоящего как точки соединения времени с вечностью; 4) мнение философа о необходимости конца истории для возможности познания исторического вкупе с экзистенциально-психологической трактовкой самого эсхатона. Вполне логичным представляется вывод о том, что преодоление «разорванного» на настоящее, прошлое и будущее времени, которое лично беспокоило Бердяева, возможно, с его точки зрения, для каждого человека уже в данный момент. Поскольку разделение времени понимается как феномен сознания, то и решение этой проблемы возможно во внутреннем мгновении настоящего, в котором пересекаются время и вечность. Так, происходит «выход» из временности в вечность, который есть не что иное как персональный «конец истории», однако он не идентичен смерти, но понимается как сознательное мгновенное трансцендирование времени - факт личной истории. Этот духовный опыт дарует человеку возможность взгляда на историю как на целое, он же освобождает человека от рабства темпоральной тотальности. Такого рода представления Бердяева мы предлагаем именовать экзистенциальным концом истории, или интериоризованным апокалипсисом, - единственным событием, позволяющим создавать метафизику истории.

\section{СПИСОК ЛИТЕРАТУРЫ}

Августин Аврелий 1991 - Августин Аврелий. Исповедь блаженного Августина, епископа Гиппонийского. М.: Ренессанс, 1991.

Безлепкин 2017 - Безлепкин Н.И. От историософии к философии истории: эволюция взглядов на историю в отечественной философской мысли // Управленческое консультирование. 2017. № 8. С. 119-132.

Бердяев 1936 - Бердяев Н.А. Лев Шестов и Киркегаард // Современныя записки. Общественно- политический и литературный журнал. LXII. Париж: [б. и.], 1936. С. 375-382.

Бердяев 1994 - Бердяев Н.А. Философия свободного духа. М.: Республика, 1994.

Бердяев 1995 - Бердяев Н.А. Царство Духа и царство Кесаря. М.: Республика, 1995.

Бердяев 1999 - Бердяев Н.А. Самопознание (Опыт философской автобиографии). М.: Книга, 1999.

Бердяев 2002 - Бердяев Н.А. Смысл истории. Новое средневековье. М.: Канон +2002.

Бродель 1977 - Бродель Ф. Философия и методология истории: сб. ст. М.: Прогресс, 1977.

Ле Гофф 2013 - Ле Гофф Ж. История и память. М.: Рос. полит. энцикл., 2013.

Кьеркегор 2014 - Кьеркегор С. Понятие страха. М.: Академ. проект, 2014.

Тиллих 1995 - Тиллих П.Й. Избранное. Теология Культуры. М.: Юрист, 1995.

Тиллих 2005 - Тиллих П.Й. Вечное сейчас (три проповеди из книги) // Вопросы философии. 2005. № 5. C. 160-164.

Moyn 2009-Moyn S. Jewish and Christian Philosophy of History / Tucker A. (eds.). A Companion to the Philosophy of History and Historiography. Hoboken: John Wiley and Sons, 2009. P. 427436. DOI: https://doi.org/10.1002/9781444304916.

\section{REFERENCES}

Augustine Aurelius, 1991. Confession of St. Augustine, Bishop of Hippo. Moscow, Renessans Publ.

Bezlepkin N.I., 2017. From Historiosophy to Philosophy of History: The Evolution of Views on History in Russian Philosophical Thought. Management Consulting, no. 8, pp. 119-132.

Berdyaev N.A., 1936. Lev Shestov and Kierkegaard. Modern Notes. Socio-Political and Literary Magazine. LXII. Paris, 1936, pp. 375-382.

Berdyaev N.A., 1994. The Philosophy of Free Spirit. Moscow, Respublika Publ.

Berdyaev N.A., 1995. The Kingdom of Spirit and the Kingdom of Caesar. Moscow, Respublika Publ.

Berdyaev N.A., 1999. Self-Knowledge (Experience of Philosophical Autobiography). Moscow, Kniga Publ.

Berdyaev N.A., 2002. The Meaning of the History. New Middle Ages. Moscow, Kanon+ Publ.

Braudel F., 1977. Philosophy and Methodology of History. Collection of Abstracts. Moscow, Progress Publ.

Goff Le J., 2013. History and Memory. Moscow, Ros. polit. entsikl. Publ.

Kierkegaard S., 2014. The Concept of Fear. Moscow, Akadem. proekt Publ. 


\section{ФИЛОСОФИЯ}

Tillich P.J., 1995. Favorites. Theology of Culture. Moscow, Yurist Publ.

Tillich P.J., 2005. The Eternal Now (Three Sermons from the Book). Questions of Philosophy, no. 5, pp. 160-164.
Moyn S., 2009. Jewish and Christian Philosophy of History. A Companion to the Philosophy of History and Historiography. Hoboken, John Wiley and Sons, pp. 427-436. DOI: https:// doi.org/10.1002/9781444304916.

\section{Information About the Author}

Artem M. Khamidulin, Candidate of Sciences (Theology), Master of Vocational Training, Senior Lecturer, Department of Bible Studies, Theology and Philosophy, Nizhny Novgorod Theological Seminary, Pokhvalinsky Syezd, 5, 603001 Nizhny Novgorod, Russian Federation; Graduate Student, Department of Philosophy and Theology, Kozma Minin Nizhny Novgorod State Pedagogical University (University of Minin), Ulyanova St, 1, 603005 Nizhny Novgorod, Russian Federation, am-khamidulin@yandex.ru, https://orcid.org/0000-0001-7741-9940

\section{Информация об авторе}

Артём Маратович Хамидулин, кандидат богословия, магистр профессионального обучения, старший преподаватель кафедры библеистики, богословия и философии, Нижегородская духовная семинария, Похвалинский съезд, 5, 603001 г. Нижний Новгород, Российская Федерация; аспирант кафедры философии и теологии, Нижегородский государственный педагогический университет им. Козьмы Минина (Мининский университет), ул. Ульянова, 1, 603005 г. Нижний Новгород, Российская Федерация, am-khamidulin@yandex.ru, https://orcid.org/0000-0001-7741-9940 